\title{
Effects of straw processing and pen overstocking on the growth performance and sorting characteristics of diets offered to replacement Holstein dairy heifers
}

\author{
W. K. Coblentz, ${ }^{* 1}$ M. S. Akins, † N. M. Esser,ł R. K. Ogden, ${ }^{*}$ and S. L. Gelsinger† \\ *USDA-Agricultural Research Service, US Dairy Forage Research Center, Marshfield, WI 54449 \\ †Department of Dairy Science, University of Wisconsin, Madison 53706 \\ ‡Marshfield Agricultural Research Station, University of Wisconsin, Marshfield 54449
}

\begin{abstract}
Our objectives were to evaluate the effects of penstocking density and straw processing on the growth performance, feed-bunk sorting behaviors, and hygiene of Holstein dairy heifers. Two corn silage-alfalfa haylage diets diluted with wheat straw were offered; diet composition was identical, except that one diet contained short (well-processed) straw (SS; $46.0 \%$ neutral detergent fiber, $12.9 \%$ crude protein, $60.7 \%$ total digestible nutrients, TDN), and the other long (poorly processed) straw (LS; $46.5 \%$ neutral detergent fiber, $12.6 \%$ crude protein, $60.0 \%$ TDN; $\%$ of dry matter basis). A $2 \times 3$ factorial arrangement of straw-processing (SS or LS) and pen-stocking-density $[100,125$, or $150 \%$ of capacity] treatments was evaluated with 240 Holstein dairy heifers $(410 \pm 56.3 \mathrm{~kg})$ that were blocked by weight, and then assigned to 24 pens with 4 pens/interactive treatment. For $91 \mathrm{~d}$, diets were dispersed at $1100 \mathrm{~h}$ daily, and bunks were sampled subsequently at 1300 , 1600, 1900, 2200, 0100, and $0600 \mathrm{~h}$ during 3 evaluation periods throughout the trial. Diets were offered for ad libitum intake, but with minimal orts $(<3 \%)$; as such, particle-size concentration factors were calculated as bunk concentration/initial concentration. For the LS diet, particle-size concentration factors for large (>19 mm) particles increased linearly from 1.26 to 2.82 across sampling times, differing from the SS diet at 2200, 0100, 0600, and $0900 \mathrm{~h}$ (orts). Similar factors calculated for the SS diet also increased linearly across sampling times, but these responses were less severe (1.27 to 1.97). Overall, particle-size concentration factors for physically effective fiber exhibited responses similar to those observed for large particles, except they were limited to narrower ranges for both the SS (1.04 to 1.14) and LS (1.03 to 1.26) diets. Despite these
\end{abstract}

Received May 19, 2017.

Accepted October 7, 2017.

${ }^{1}$ Corresponding author: wayne.coblentz@ars.usda.gov differences, daily dry matter intake was not affected by treatment $($ mean $=9.65 \mathrm{~kg}$ of dry matter $/ \mathrm{d})$, nor was daily intake of TDN (mean $=5.92 \mathrm{~kg}$ of TDN/d). For SS, heifers housed within overstocked pens exhibited reduced average daily gain (ADG) compared with the $100 \%$ stocking rate $(0.93$ vs. $0.99 \mathrm{~kg} / \mathrm{d})$. With LS processing, ADG differed between the 125 and $150 \%$ stocking rates (0.96 vs. $0.88 \mathrm{~kg} / \mathrm{d}$ ), as did the withinpen coefficient of variation for ADG (10.7 vs. 18.6\%). Hygiene scores $(1=$ clean, $4=$ caked-on manure $)$ for legs $($ range $=2.1$ to 2.3 ) and flanks (range $=1.6$ to 1.9 ) indicated heifers stayed acceptably clean, but the within-pen coefficient of variation for legs (14.4 vs. 9.0\%) and flanks (34.2 vs. $23.8 \%$ ) was greater for overstocked pens compared with the $100 \%$ stocking density, thereby suggesting hygiene scores were more variable without a free stall for each heifer.

Key words: Holstein dairy heifer, sorting behavior, stocking density, wheat straw

\section{INTRODUCTION}

Management programs for dairy replacement heifers generally seek to raise replacement animals at a low economic and environmental cost without compromising their subsequent performance as lactating cows (Hoffman et al., 2007). Most often, diets for dairy heifers are forage based, especially for gravid animals, whose requirements for energy are less than those of younger heifers (NRC, 2001). In many dairy operations, corn silage is readily available, but becomes problematic for gravid heifers when it comprises large proportions of the total diet offered for ad libitum intake. Frequently, this results in excessive weight gains and over-conditioning; in 2 recent trials we conducted, heifers offered negative control diets comprising approximately 50:50 blends (DM basis) of corn silage and alfalfa haylage gained 1.16 and $1.09 \mathrm{~kg} / \mathrm{d}$ (Coblentz et al., 2012, 2015), which exceeds frequently suggested daily growth targets for gravid heifers (Hoffman, 1997) by approximately 0.25 
to $0.30 \mathrm{~kg} / \mathrm{d}$. There are compounding causes for excessive weight gains under these conditions: (1) normal corn silage is energy dense (68.8\% TDN; NRC, 2001), and exceeds the energy requirements for gravid heifers; and (2) corn silage contains inadequate NDF (45\%; NRC, 2001) for suppression of voluntary intake. Hoffman et al. (2008) has determined that voluntary intake by heifers is limited to approximately $1.0 \%$ of $\mathrm{BW}$ daily as NDF; therefore, high proportions of corn silage permit greater voluntary intakes of high-energy forage DM before meeting the daily NDF constraint required to limit intake via gut fill.

Generally, 2 approaches are used for maintaining daily weight gains within acceptable ranges and avoiding subsequent over-conditioning: (1) dilution of the ad libitum diet with low-energy forages, such as chopped straw, corn fodder, or perennial warm-season grasses (Hoffman et al., 1996; Greter et al., 2008; Coblentz et al., 2015); or (2) offering a diet of greater energy density, but deliberately restricting the amount of feed available for consumption (limit-feeding; Hoffman et al., 2007; Zanton and Heinrichs, 2007, 2008; Kruse et al., 2010). Potential advantages of dilution with lowenergy forages include the option of formulating diets containing energy densities that meet specific producer goals for growth, reducing feed costs, and allowing opportunities for natural foraging behaviors (Greter et al., 2008). Limit-feeding management has demonstrated increased digestibilities via slower passage rates and greater residence times in the digestive tract (Loerch, 1990), reduced fecal outputs, and improved overall feed efficiencies (Hoffman et al., 2007; Kruse et al., 2010). Disadvantages of limit-feeding include increased vocalization and standing time (Hoffman et al., 2007); in addition, the combination of inadequate bunk length coupled with limit-feeding management has been shown to increase variability of individual growth rates within the pen, but not necessarily the mean growth rate of the group (Longenbach et al., 1999). Largely, this variability has been explained on the basis of increased social tension within the pen group, as well as inadequate opportunity for some heifers to consume adequate nutrients, which can be complicated further by the dominant and subordinate personalities expressed by heifers or cows (Longenbach et al., 1999; DeVries et al., 2004). Under such circumstances, smaller or less aggressive heifers could be forced to accept the consequences of their social position (Longenbach et al., 1999). The inclusion of low-energy forages can permit heifers to aggressively sort against less desirable, low-energy dilutants or longer particles (Greter et al., 2008). Furthermore, sorting behaviors are forage specific. A recent study by our group (Coblentz et al., 2015) indicated that chopped corn fodder is extremely sortable, whereas eastern gamagrass [Tripsacum dactyloides (L.) L.] haylage is largely unsortable, and chopped wheat straw is intermediate with respect to heifer preference. By ensuring feed is always present in the bunk, ad libitum feeding of diets diluted with low-energy forages has the benefit of reducing animal frustration, such as the increased vocalization observed for limit-fed heifers (Hoffman et al., 2007). However, it also may increase within-pen variability with respect to animal performance, particularly when confounded by overstocking coupled with dominant and subordinate heifer personalities. Under these conditions, feeding behaviors are altered, and the diet actually consumed by various heifers within the pen may be unbalanced (DeVries and von Keyserlingk, 2009) with dominant animals discriminating against low-energy dilutant forages, and passive heifers forced to accept these forages as a greater percentage of their diet. In an effort to mediate these within-pen dynamics, extension recommendations (Shaver and Hoffman, 2010) have included (1) using a bale chopper or tub grinder to limit long particles to $\leq 7.5 \mathrm{~cm}$ in length; (2) always blending straw or other similar dilutants within a TMR mixer; and (3) adhering to close management coordination of voluntary intake with regular feed allotments, such that the diet is totally consumed before additional feed is dispersed.

Our objectives for this study were to examine the effects of straw processing and overstocking of pens on nutrient intakes, growth performance, feed-bunk sorting behaviors, and the hygiene of Holstein dairy replacement heifers.

\section{MATERIALS AND METHODS}

\section{Housing, Animals, and Diets}

Animals. All animal handling procedures for this experiment were approved by the Research Animal Resources Committee of the University of WisconsinMadison (protocol \#A005189). Two hundred forty Holstein heifers $(410 \pm 56.3 \mathrm{~kg})$ were blocked by weight, and then assigned to 1 of 24 identical research pens (6 pens/block). Stocking densities were established by assigning 8,10 , or 12 heifers to a pen, which correspond to pen stocking rates of 100,125 , or $150 \%$, respectively, at both the feed bunk, and with respect to available free stalls.

Housing. Each research pen was configured with continuous access to fresh water, an automated mechanical alley-scraping system, 8 free stalls with foamcore mattresses covered with a shallow layer of dried organic solids, and 8 head-locking feeding gates positioned adjacent to a drive-by feed alley. Head-locking feeding gates allowed for a total of $4.9 \mathrm{~m}$ of linear bunk 
space, or $0.61 \mathrm{~m} /$ heifer, based on a maximum of 8 heifers eating simultaneously. Head-locking feed gates were set to allow freedom to access the feed bunk at any time unless gates were occupied by another heifer. The size of each research pen (including free stalls) was 7.9 $\times 10.7 \mathrm{~m}$, for a total area of $84.5 \mathrm{~m}^{2} /$ pen; therefore, calculated areas on a per heifer basis were 10.6, 8.5, and $7.0 \mathrm{~m}^{2}$ for the 100,125 , and $150 \%$ stocking rates, respectively. Free stalls in each pen were arranged in 2 head-to-head rows of 4 stalls; each pen also contained a crossover alley so that heifers lounging in all stalls had free access to the feeding gates. Each free stall was supplied with a thin layer $(\sim 2$-cm depth) of dried organic solids approximately every $10 \mathrm{~d}$. Stalls and crossover alleys were raked or scraped daily to remove any feces or wet bedding soiled by urine. Automatic alley scrapers were set to clean each pen every $2 \mathrm{~h}$ during daylight hours. Alley scrapers were turned off at night to prevent injury potentially associated with overstocked pens and dark conditions in the barn.

Diets. Diets were formulated identically (Table 1), and comprised (DM basis) alfalfa haylage (51.9\%), corn silage $(33.5 \%)$, and wheat straw $(14.6 \%)$. The diets differed only with respect to the protocol by which wheat straw was prepared: (1) by pre-processing through a 10-cm screen (short straw; SS) in a Haybuster Model 1100 tub grinder (DuraTech Industries International Inc., Jamestown, ND) or (2) with no pre-processing (long straw; LS), where flakes obtained from largerectangular bales of wheat straw were placed directly into the vertical TMR mixer (model 585, Meyer Manufacturing Corp., Dorchester, WI). The goal of these procedures was to create diets with similar nutrient compositions, but to represent different management scenarios where the straw differed distinctly with respect to particle length, and subsequent sortability. Both experimental diets were blended in the TMR with shear plates extracted. For LS, straw was added to the mixer first, followed by the other dietary components. All components were then blended for 1 min before dispersing; these procedures were adopted to simulate poor processing, and poor overall management of straw in TMR diets. For SS, all dietary components were added to the mixer, and then blended for 3 min before feeding. Diets were dispensed to each pen once daily at approximately $1100 \mathrm{~h}$, and then pushed back within easy reach of the heifers at least twice daily before orts were gathered at $0900 \mathrm{~h}$ the following morning.

Both experimental diets were offered for ad libitum intake for the duration of the study (91 d); however, feed bunks were evaluated each morning and managed to a defined bunk score of 2 , where $0=$ no feed particles remaining, 1 = only scattered feed particles remaining, $2=$ numerous particles remaining, but the concrete floor still easily visible, or $3=$ feed particles covering the floor of the bunk completely (Hoffman et al., 2008). This management system was used to provide an objective basis for adjusting the daily amount of TMR dispersed such that voluntary intake was not limited, but only a minimal amount of orts was recovered each day, which is consistent with recommendations for including straw in TMR diets (Shaver and Hoffman, 2010). Normally, the management response to a bunk score of 0 was a $6 \%$ increase in the daily diet allocation calculated on an as-fed basis; the typical response to bunk scores of 1 and 3 were a $3 \%$ increase and decrease, respectively. Diet samples were obtained daily, sealed in plastic freezer bags, stored at $-20^{\circ} \mathrm{C}$, and composited by week for nutritive analysis. Orts were collected from each pen daily at approximately $0900 \mathrm{~h}$, weighed in a large plastic tub, subsampled, frozen at $-20^{\circ} \mathrm{C}$ in sealed freezer bags, and composited by week. A 400-g subsample of the weekly diet and ort composites was dried to constant weight $(\sim 96 \mathrm{~h})$ under forced air at $55^{\circ} \mathrm{C}$ to determine mean weekly concentrations of DM within these composites.

\section{Laboratory Analysis of Diets}

Diet composites were dried $\left(55^{\circ} \mathrm{C}\right)$ each week under forced air to constant weight, and then ground through a 1-mm screen in a Thomas Model 4 Wiley Mill (Thomas Scientific, Swedesboro, NJ). Samples then were analyzed by the University of Wisconsin Soil and Forage Laboratory (Marshfield, WI) for (1) ash, after combustion in a muffle furnace at $500^{\circ} \mathrm{C}$ for $6 \mathrm{~h}$; (2) $\mathrm{CP}$ (AOAC International, 1998a; Official Method 988.05); (3) $\mathrm{Ca}, \mathrm{K}$, and $\mathrm{Mg}$ by atomic absorption spectroscopy; (4) P (Schulte et al., 1987); (5) starch (model 2700D, Yellow Springs Instrument Co., Yellow Springs, OH); and (6) fat (AOAC, 1990; Official Method 920.29). Diet NDF concentrations were quantified by the methods of Goering and Van Soest (1970) with both heat-stable $\alpha$-amylase and sodium sulfite included within the NDF solution. A 48-h in vitro digestion of NDF was conducted in buffered rumen fluid (NDFD) using procedures described in detail by Kruse et al. (2010) and Coblentz et al. (2012). Diet samples obtained during wk $1,5,9$, and 13 of the trial were analyzed in greater detail for concentrations of ADF and ADL (Goering and Van Soest, 1970) without preliminary digestion in neutral detergent. At the same time, independent NDF and ADF residues were obtained following direct digestion in neutral- and acid-detergent solutions, respectively. Subsequently, fiber residues were analyzed for residual CP (NDICP and ADICP, respectively) as described previously. For NDICP, the neutral-detergent procedures included use of heat-stable $\alpha$-amylase for 
Table 1. Ingredient composition of experimental diets, and mean nutrient composition based on weekly analysis (13 wk) by the University of Wisconsin Soil and Forage Analysis Laboratory (Marshfield)

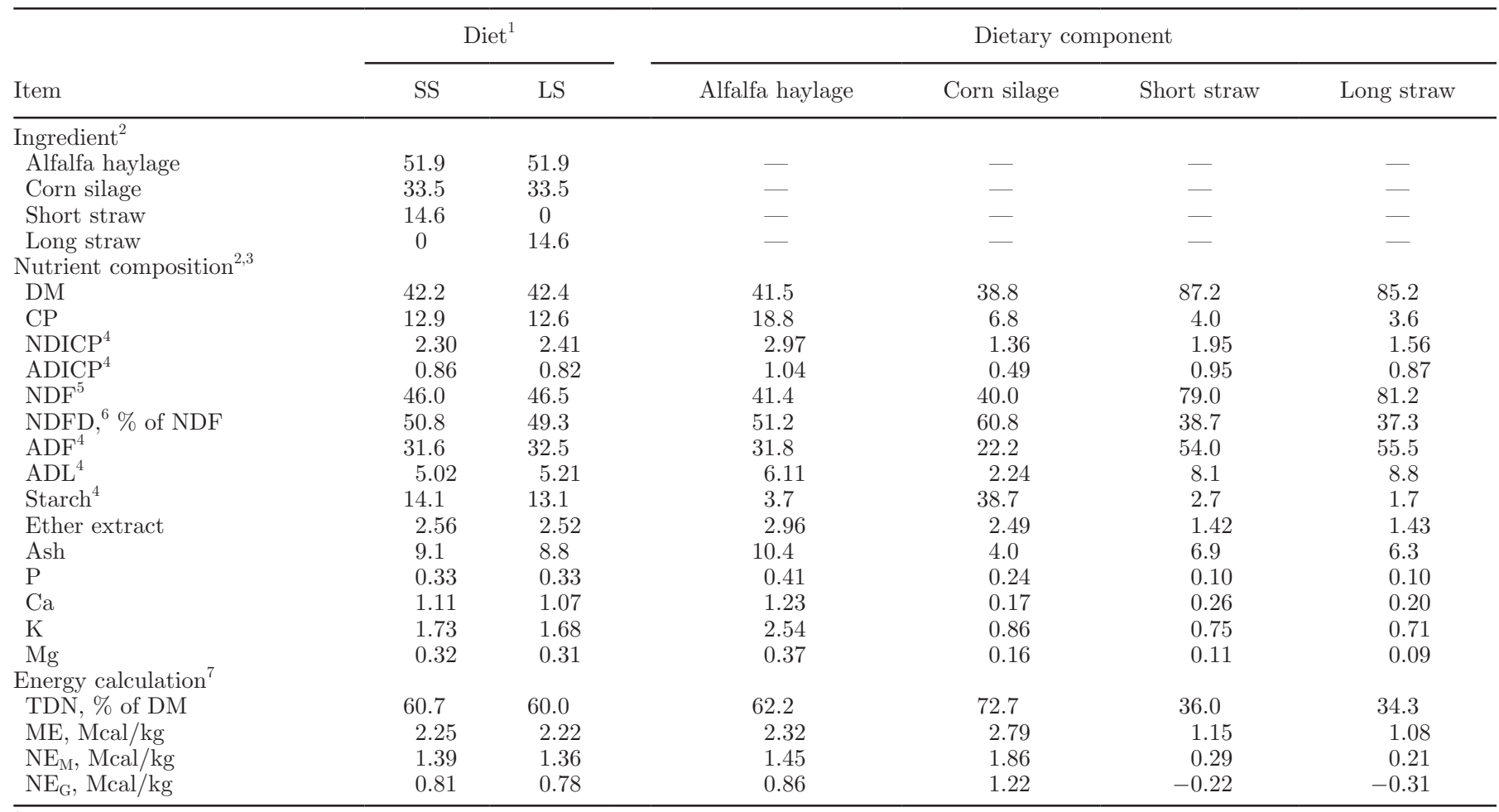

${ }^{\mathrm{i}} \mathrm{SS}=$ diet included wheat straw pre-processed through a tub grinder (10-cm screen) before blending into a TMR; LS = diet included unprocessed wheat straw blended into a TMR.

${ }^{2} \mathrm{All}$ ingredients or nutrients are expressed on a $\%$ of DM basis unless otherwise noted.

${ }^{3}$ Mineral package contained $72.1 \%$ calcium carbonate, $16.5 \%$ salt, $3.35 \%$ sulfur, $2.95 \%$ selenium $1600,1.50 \%$ vitamin A, $0.75 \%$ mineral oil, $0.71 \%$ copper sulfate, $0.69 \%$ vitamin E (50\%), $0.64 \%$ zinc sulfate, $0.51 \%$ vitamin D, $0.09 \%$ iodine mix, $0.005 \%$ magnesium sulfate, $0.005 \%$ cobalt carbonate, $0.005 \%$ manganese oxide $(60 \%)$, and $0.26 \%$ thiamine. Mineral package was blended into the total diet at a rate of $158 \mathrm{~g} /$ heifer per day and delivered within the TMR.

${ }^{4}$ Concentrations of ADF, ADL, starch, neutral detergent insoluble crude protein (NDICP), and acid detergent insoluble crude protein (ADICP) were determined for wk $1,5,9$, and 13 of the trial.

${ }^{5}$ Neutral-detergent solution contained both heat-stable $\alpha$-amylase and sodium sulfite.

${ }^{6} \mathrm{NDFD}$ (NDF digestibility) determined following a 48-h digestion in buffered rumen fluid.

${ }^{7}$ Energy calculations based on NRC (2001).

removal of starch, but sodium sulfite was omitted, thereby preventing excessive solubilization of CP from the forage fiber matrix (Van Soest et al., 1991). Total digestible nutrients were calculated based on the summative model (NRC, 2001), where the 48-h NDF digestibility was used as a digestibility coefficient for NDF to estimate truly digestible fiber. Subsequently, other measures of energy $\left(\mathrm{ME}, \mathrm{NE}_{\mathrm{G}}\right.$, and $\left.\mathrm{NE}_{\mathrm{M}}\right)$ were calculated as indicated by NRC (2001).

The mean DM refusal rate averaged across all pens and all days during the 91-d trial was $2.75 \%$ of the feed offered, which could potentially affect nutrient intakes disproportionately in a trial where diets were prepared intentionally to create different sorting behaviors by heifers. A single composite ort sample was created for each research pen based on equal contributions from the weekly ort composites described previously. These samples were submitted to the University of Wisconsin Soil and Forage Laboratory for the identical analyses described for diet samples. Actual DM refusals and the associated nutrient composition of orts were then used to determine nutrient intakes for each individual research pen by subtracting the amount of each nutrient refused from the amount offered.

\section{Feed Bunk Assessment of Changes in Particle Size and Nutritive Value}

Sampling Procedures. Heifer sorting behaviors for the SS and LS diets were assessed by sampling feed bunks across 3 evaluation periods that were scheduled during wk 4, 8 , and 12 of the trial; each evaluation period was $6 \mathrm{~d}$ in length. Following discharge of the TMR at approximately $1100 \mathrm{~h}$ each morning, bunks 
were sampled at 1300, 1600, 1900, 2200, 0100, or 0600 $\mathrm{h}$; however each bunk was sampled only once daily to minimize the disruption of eating and sorting behaviors. Across each 6-d evaluation period, sampling times for each pen were randomized, such that each designated sampling time was assigned randomly to one specific day during each evaluation period.

Sampling procedures were similar to those described previously (Coblentz et al., 2015). Briefly, each feed bunk was arbitrarily divided between the 4th and 5th head-locking gate. At one randomly selected location within each half of the bunk, a scoop shovel was used to remove all the feed that intersected the shovel width starting at the feed alley and continuing to the concrete curb on which the head-locking gates were mounted. These large samples for each pen were thoroughly mixed in a large plastic tub. A subsample $(\sim 1,000 \mathrm{~g})$ was removed from the tub, sealed in a 3.8-L freezer bag, and frozen $\left(-20^{\circ} \mathrm{C}\right)$ pending subsequent evaluation of particle size distribution and nutritive value. Samples of the experimental diets (LS and SS), as well as orts collected from each pen, were obtained from the regular weekly sampling procedures described previously, and then frozen $\left(-20^{\circ} \mathrm{C}\right)$ to further supplement particle size distribution analysis.

Particle Size Distribution and Nutritive Value. Diets, bunk samples, and orts were assessed for particle size distribution with a Penn State Particle Separator using a 3 -screen system $(19,8$, and $1.18 \mathrm{~mm})$ for fractionation (Kononoff et al., 2003). On this basis, forage particles were separated into 4 fractions: (1) large, $>19 \mathrm{~mm}$; (2) medium, <19 and >8 mm; (3) short, $<8$ and $>1.18 \mathrm{~mm}$; and (4) fine, $<1.18 \mathrm{~mm}$. Relative percentages of DM associated with each particle size fraction were calculated after drying overnight in a convection oven at $105^{\circ} \mathrm{C}$. Physically effective fiber (pef) was defined, and calculated, as the percentage of total DM retained on the top 2 screens (19 and 8 $\mathrm{mm}$ ) of the Penn State Particle Separator (Lammers et al., 1996). Concentration factors were calculated as the concentration of each particle size fraction in the feed bunk divided by the concentration of that fraction in the original TMR. As such, factors equal to 1.00 suggest no preference, whereas factors $>1.00$ or $<1.00$ suggest discrimination or preference by heifers, respectively. Other studies (Leonardi and Armentano, 2003; Greter et al., 2008; DeVries and von Keyserlingk, 2009) have described sorting as the actual DMI of each fraction expressed as a percentage of the predicted DMI of that fraction. As described previously, our feeding procedures are based on a bunk-scoring system that permits ad libitum intake, but minimizes orts. Aver- aged across the entire trial, orts comprised only 2.76 and $2.74 \%$ of all feed dispersed (DM basis) for SS and LS diets, respectively. Effectively, this renders sorting factors calculated on the basis of predicted and actual DMI (Leonardi and Armentano, 2003) of little value because there is essentially complete consumption of diets, thereby ensuring that predicted and actual DMI of any feed fraction within a 24 -h time period will be almost identical. Furthermore, sorting factors based on predicted and actual DMI at specific sampling times would require continuous, and likely electronic, measurement of feed remaining in each bunk, which was not feasible given the scope (24 pens) of the trial.

In addition to evaluations of particle size distribution, bunk samples were evaluated sequentially for NDF and ADL by procedures outlined for an ANKOM200 Fiber Analyzer (Ankom Technology Corp., Macedon, NY). Concentrations of CP for each bunk sample were determined by rapid combustion methodology (AOAC International, 1998b, Official Method 990.03; Model TruMac CN, Leco Corp., St. Joseph, MI). Concentrations of residual $\mathrm{CP}$ within $\mathrm{NDF}$ and $\mathrm{ADF}$ residues (NDICP and ADICP) were determined similarly, following nonsequential extractions in neutral and acid detergent, respectively. To avoid destruction of lignin, and to prevent excessive removal of CP from the forage fiber matrix, sodium sulfite was omitted from these NDF-extraction procedures (Van Soest et al., 1991). Ash concentrations were quantified by combustion of 1.0 -g samples at $500^{\circ} \mathrm{C}$ for $6 \mathrm{~h}$. These inputs were used to calculate energy density (TDN) by the summative approach (NRC, 2001) using the ADL option to calculate truly digestible fiber. Nutrient concentration factors for NDF, CP, ADL, and TDN were then calculated as described previously for various particle size classes, where values $<1.00$ or $>1.00$ suggest preference or discrimination by heifers, respectively.

\section{Body Measurements}

Initial heifer BW were obtained on 3 consecutive mornings immediately before feed was delivered using a cattle chute (Real Tuff, Clearbrook, MN) equipped with an electronic scale (Tru-Test Inc., Mineral Wells, TX). The initial BW for each heifer was calculated as the mean of the 3 daily BW obtained immediately before the trial began. Final heifer BW were obtained in an identical manner after $91 \mathrm{~d}$. During the initial and final 3-d weighing periods, each heifer was measured for heart girth, body length, hip height, and hip width (Esser et al., 2009). Body condition scores were assessed concurrently by 2 trained evaluators using a scale of 1 
to 5 , where $1=$ emaciated and $5=$ obese (Wildman et al., 1982). For BCS, increments of 0.5 units were applied to best describe the body condition of each heifer.

\section{Standing Time Assessments}

Total daily standing time, standing time per bout, and total number of standing bouts were obtained electronically (Ito et al., 2009) by attaching a Hobo Pendant G Data Logger (model UA-004-64, Onset Computer Corp., Bourne, MA) to the inside of the right-hind leg of each heifer using Vet Wrap (Co-Flex, Andover Coated Products Inc., Salisbury, MD). Data loggers were set to record information for $7 \mathrm{~d}$ before they were removed from each animal. Data were averaged over $7 \mathrm{~d}$ to establish a mean response over the 7 - $d$ recording period. This process was conducted during wk 6 and 13 of the trial; therefore, the pen mean for each response variable consisted of 2 evaluation periods $\times 7 \mathrm{~d} \times$ number of heifers/pen $(8,10$, or 12$)$, which equates to 112,140 , or 168 individual daily observations/pen.

\section{Hygiene Assessments}

At one point during each bunk-sampling period, all heifers were scored for cleanliness (hygiene) of flanks and legs using the 4-point system of Cook and Reinemann (2007), where $1=$ heifers free from manure and $4=$ heifers covered with caked-on manure. Scores were taken by 2 trained technicians during each bunk-sampling period; therefore, each heifer was scored 6 times during the trial.

\section{Statistics}

All data were analyzed by PROC MIXED procedures of SAS (2010, version 9.3, SAS Institute Inc., Cary, $\mathrm{NC}$ ) using a randomized complete block design with a 2 diet (SS or LS) $\times 3$ stocking rate $(100,125$, or $150 \%)$ arrangement of treatments, and 4 blocks (replications). In all cases, the pen served as the experimental unit (St-Pierre, 2007), thereby permitting 23 total degrees of freedom. Because heifers initially were blocked on the basis of weight, experimental blocks or replications were considered a fixed, rather than a random variable. Other fixed effects included diet, stocking rate, and their interaction. Generally, orthogonal contrasts were used to test the effects of treatment, and included (1) SS versus LS; (2) 100\% stocking versus overstocking (125 and 150\%); and (3) 125 versus $150 \%$ overstocking. To analyze bunk samples following feed distribution, the experimental design was expanded to a split plot with diets considered whole plots and bunk-sampling times [1300, 1600, 1900, 2200, $0600 \mathrm{~h}$, and orts (0900 h)] designated as subplots. Orthogonal contrasts designed to test for linear and quadratic effects of time from feeding $(1100 \mathrm{~h})$ were used to describe the daily trends in particle size or nutrient concentration factors. The PROC IML of SAS (2010) was used to adjust polynomial coefficients for uneven spacing of bunk-sampling times to maintain orthogonality. Statistical significance was declared at $P<0.05$, whereas trends of interest are described when $P<0.10$.

\section{RESULTS AND DISCUSSION}

\section{Diet Composition and Nutrient Intakes}

The LS and SS diets were formulated identically, differing only in the processing of wheat straw (Table 1). Thus, diets varied minimally with respect to most nutrient concentrations, and reasonably achieved goals of delivering isonitrogenous (12.9 and $12.6 \% \mathrm{CP})$ and isocaloric (60.7 and $60.0 \%$ TDN) nutrient concentrations. Nutrient intakes were affected only minimally by diet. Neither pen stocking density, nor the pen stocking density $\times$ diet interaction, affected $(P \geq 0.235)$ the intake of any nutrient; therefore, only main effect means for diet are presented and discussed (Table 2). Although the magnitude of differences was small, effects of diet were observed for CP $(P=0.042)$, starch $(P<0.001)$, ash $(P=0.001)$, Ca $(P<0.001)$, and $\mathrm{Mg}(P=0.009)$, with greater intakes observed in each case for the SS diet. Of these, the most substantial difference was observed for the intake of starch, which amounted to about $0.1 \mathrm{~kg} / \mathrm{d}$; however, no difference was observed with respect to intake of TDN (mean = $5.92 \mathrm{~kg} / \mathrm{d} ; P=0.164)$ or other measures of dietary energy density $(P \geq 0.069)$. Daily intakes of NDF across diets were almost identical (mean $=4.48 \mathrm{~kg} / \mathrm{d}$; $P=0.843$ ), and based on an approximated mid-point trial weight for heifers offered SS $(453 \mathrm{~kg}$ ) or LS diets $(451 \mathrm{~kg})$, calculated NDF intakes on a percentage of BW basis were $0.99 \%$ in both cases, which corresponds very closely to the $1.0 \%$ of $\mathrm{BW}$ limit for daily intake of NDF proposed by Hoffman et al. (2008). Several other studies have indicated that competition for feed offered for ad libitum intake may affect feeding behaviors, but this often has had limited or no effect on daily DMI by heifers (DeVries and von Keyserlingk, 2009), lactating cows (Olofsson, 1999), or transition cows (Proudfoot et al., 2009). Generally, these previous observations are corroborated by the present work, most notably by the lack of a stocking density main effect for voluntary DMI $($ mean $=9.65 \mathrm{~kg}$ of DM $/ \mathrm{d} ; P=0.419)$. 


\section{Heifer Growth and Performance}

Main effects of diet and stocking density minimally affected heifer growth performance, but the interaction of these effects was significant for numerous response variables. As such, initial and final body measurements, as well as all growth performance data are reported (Table 3) and discussed as stocking density $\times$ diet interaction means.

SS Diet. As expected, only minimal differences were observed across treatments for initial body measurements. Initial body length of heifers assigned to pens offered the SS diet and stocked at $100 \%$ of capacity was greater than observed for overstocked pens (147 vs. 145 $\mathrm{cm} ; P=0.046)$, but no other contrast comparing initial body measurements for heifers offered the SS diet was detected $(P \geq 0.053)$. Final BW was greater for heifers offered the SS diet in pens stocked at $100 \%$ of capacity compared with overstocked pens (501 vs. $494 \mathrm{~kg} ; P=$ 0.031); however, overstocked pens only tended to differ $(P=0.095)$, with the $150 \%$ stocking rate exhibiting a numerical advantage (497 vs. $491 \mathrm{~kg}$ ). Similarly, final BCS was greater for heifers in pens stocked at $150 \%$ compared with $125 \%$ of capacity (3.57 vs. $3.39 ; P=$ $0.023)$, but no other final body measurement differed $(P \geq 0.128)$ among heifers offered the SS diet. Total weight gain (90 vs. $84 \mathrm{~kg} ; P=0.008$ ) and ADG (0.99 vs. $0.93 \mathrm{~kg} / \mathrm{d} ; P=0.009)$ both were greater for heifers in pens stocked at $100 \%$ of capacity compared with

Table 2. Nutrient intakes for replacement heifers consuming TMR diets with (SS) or without (LS) pre-processing of straw through a 10$\mathrm{cm}$ screen in a tub grinder

\begin{tabular}{|c|c|c|c|c|}
\hline \multirow[b]{2}{*}{ Item } & \multicolumn{2}{|c|}{ Diet } & \multirow[b]{2}{*}{ SEM } & \multirow[b]{2}{*}{$P>F$} \\
\hline & SS & LS & & \\
\hline \multicolumn{5}{|l|}{ Nutrient intake } \\
\hline $\mathrm{DM}, \mathrm{kg} / \mathrm{d}$ & 9.68 & 9.61 & 0.083 & 0.542 \\
\hline $\mathrm{OM}, \mathrm{kg} / \mathrm{d}$ & 8.80 & 8.76 & 0.078 & 0.723 \\
\hline $\mathrm{CP}, \mathrm{kg} / \mathrm{d}$ & 1.26 & 1.23 & 0.011 & 0.042 \\
\hline $\mathrm{NDF}, \mathrm{kg} / \mathrm{d}$ & 4.48 & 4.47 & 0.044 & 0.843 \\
\hline Digestible NDF ${ }^{1} \mathrm{~kg} / \mathrm{d}$ & 2.28 & 2.22 & 0.019 & 0.051 \\
\hline $\mathrm{ADF}, \mathrm{kg} / \mathrm{d}$ & 3.08 & 3.13 & 0.032 & 0.307 \\
\hline Starch, kg/d & 1.39 & 1.29 & 0.011 & $<0.001$ \\
\hline Ether extract, $\mathrm{kg} / \mathrm{d}$ & 0.25 & 0.25 & 0.003 & 0.056 \\
\hline $\mathrm{Ash}, \mathrm{kg} / \mathrm{d}$ & 0.89 & 0.86 & 0.006 & 0.001 \\
\hline $\mathrm{P}, \mathrm{g} / \mathrm{d}$ & 32 & 32 & 0.4 & 0.628 \\
\hline $\mathrm{Ca}, \mathrm{g} / \mathrm{d}$ & 111 & 105 & 0.8 & $<0.001$ \\
\hline $\mathrm{K}, \mathrm{g} / \mathrm{d}$ & 170 & 164 & 2.0 & 0.056 \\
\hline $\mathrm{Mg}, \mathrm{g} / \mathrm{d}$ & 32 & 30 & 0.3 & 0.009 \\
\hline \multicolumn{5}{|l|}{ Energy intake ${ }^{2}$} \\
\hline TDN, kg/d & 5.97 & 5.87 & 0.050 & 0.164 \\
\hline $\mathrm{ME}, \mathrm{Mcal} / \mathrm{d}$ & 21.9 & 21.6 & 0.17 & 0.227 \\
\hline $\mathrm{NE}_{\mathrm{G}}, \mathrm{Mcal} / \mathrm{d}$ & 7.9 & 7.7 & 0.06 & 0.069 \\
\hline $\mathrm{NE}_{\mathrm{M}}, \mathrm{Mcal} / \mathrm{d}$ & 13.5 & 13.3 & 0.103 & 0.159 \\
\hline
\end{tabular}

${ }^{1}$ Values based on NDF intakes, and a 48-h in vitro determination of NDF digestibility.

${ }^{2}$ Energy calculations based on NRC (2001). those overstocked, but overstocked rates did not differ $(P \geq 0.728)$ in either case. A similar response to overstocking was observed for the change in hip width (6.7 vs. $4.8 \mathrm{~cm} ; P=0.008)$, but overstocked rates did not differ $(P=0.739)$. Feed efficiency (feed/gain; $\mathrm{kg} / \mathrm{kg}$ ) was poorer with overstocking among heifers offered the SS diet (10.6 vs. $9.6 \mathrm{~kg} / \mathrm{kg} ; P=0.005)$, but as observed for other response variables, no difference was observed $(P=0.935)$ between the 125 and $150 \%$ stocking rates. The only detectable contrast for comparisons of the 125 and $150 \%$ stocking rates among growth measurements was observed for change in body length, which was greater for the $125 \%$ stocking rate $(8.5$ vs. $5.2 \mathrm{~cm}$; $P=0.028)$.

LS Diet. Initial hip height was greater for overstocked pens compared with those stocked at $100 \%$ of capacity (137 vs. $135 \mathrm{~cm} ; P=0.007$ ), but all other initial body measurements did not differ $(P \geq 0.058)$. Research pens stocked at $125 \%$ of capacity exhibited a greater final BW than the $150 \%$ stocking rate (497 vs. $489 \mathrm{~kg} ; P=0.041$ ), but no other significant contrasts $(P \geq 0.080)$ were detected for any other final body measurement among heifers offered the LS diet. In contrast to the SS diet, no comparison of the $100 \%$ stocking rate with overstocked rates for any measurement of growth or feed efficiency was significant $(P \geq 0.103)$. However, contrasts comparing overstocked rates were detected for total weight gain ( 87 vs. $80 \mathrm{~kg} ; P=0.006)$, ADG (0.96 vs. $0.88 \mathrm{~kg} / \mathrm{d} ; P=0.005)$, heart girth (12 vs. $10 \mathrm{~cm} ; P$ $=0.034)$, and BCS (0.39 vs. $0.15 ; P=0.042)$, with the greater change for each growth response occurring for the $125 \%$ stocking rate. In addition, there was also a tendency for greater feed efficiency for heifers stocked at $125 \%$ compared with $150 \%$ of capacity (10.2 vs. 10.8 $\mathrm{kg} / \mathrm{kg} ; P=0.062)$.

\section{Within-Pen Variability for ADG}

Based on previous work (Longenbach et al., 1999; González et al., 2008a), within-pen variability with respect to ADG might be expected to increase with stocking rate, irrespective of effects on mean daily weight gains for the entire pen. This hypothesis is based on known effects of competition on feeding behavior, such as reducing total daily feeding time, increased feed consumption rates, increased time spent inactively standing, and greater numbers of displacements from the feed bunk (Keys et al., 1978; Olofsson, 1999; Huzzey et al., 2006; DeVries and von Keyserlingk, 2009). Furthermore, dominant and subordinate relationships become more defined as competition for feed increases; in particular, animals of lower social rank are more likely to be displaced from the feed bunk while eating (Olofsson, 1999; Huzzey et al., 2006). To assess 
Table 3. Effects of diet and pen-stocking rate on body size and growth performance of 240 Holstein replacement heifers

\begin{tabular}{|c|c|c|c|c|c|c|c|c|c|c|c|}
\hline Item & \multicolumn{6}{|c|}{ Stocking density, ${ }^{1} \%$} & \multicolumn{5}{|c|}{ Contrast $^{2}$} \\
\hline \multicolumn{12}{|l|}{ Initial } \\
\hline $\mathrm{BW}, \mathrm{kg}$ & 411 & 407 & 413 & 407 & 410 & 409 & 2.0 & 0.625 & 0.053 & 0.472 & 0.777 \\
\hline Length, cm & 147 & 144 & 145 & 144 & 147 & 144 & 0.8 & 0.046 & 0.241 & 0.367 & 0.058 \\
\hline Heart girth, cm & 175 & 175 & 176 & 176 & 175 & 175 & 0.5 & 0.130 & 0.171 & 0.264 & 0.639 \\
\hline BCS & 3.17 & 3.19 & 3.28 & 3.19 & 3.05 & 3.18 & 0.060 & 0.369 & 0.329 & 0.320 & 0.143 \\
\hline \multicolumn{12}{|l|}{ Final } \\
\hline BW, kg & 501 & 491 & 497 & 491 & 497 & 489 & 2.5 & 0.031 & 0.095 & 0.570 & 0.041 \\
\hline Length, cm & 152 & 152 & 151 & 150 & 151 & 150 & 0.9 & 0.775 & 0.152 & 0.514 & 0.307 \\
\hline Hip width, cm & 51 & 50 & 50 & 50 & 50 & 50 & 0.4 & 0.184 & 0.271 & 0.520 & 0.271 \\
\hline Hip height, $\mathrm{cm}$ & 141 & 141 & 140 & 140 & 141 & 141 & 0.6 & 0.274 & 0.341 & 0.177 & 0.630 \\
\hline \multicolumn{12}{|l|}{ Growth } \\
\hline $\mathrm{CV},{ }^{4} \%$ & 13.1 & 18.2 & 15.0 & 9.9 & 10.7 & 18.6 & 2.24 & 0.220 & 0.317 & 0.103 & 0.025 \\
\hline Length, $\mathrm{cm}$ & 5.0 & 8.5 & 5.2 & 5.5 & 4.8 & 5.8 & 0.96 & 0.137 & 0.028 & 0.873 & 0.465 \\
\hline Hip width, cm & 6.7 & 4.6 & 4.9 & 4.3 & 4.7 & 3.8 & 0.53 & 0.008 & 0.739 & 0.923 & 0.252 \\
\hline Hip height, cm & 4.3 & 4.0 & 3.4 & 4.8 & 3.9 & 4.6 & 0.59 & 0.396 & 0.461 & 0.495 & 0.461 \\
\hline Heart girth, cm & 11 & 9 & 10 & 10 & 12 & 10 & 0.4 & 0.110 & 0.376 & 0.110 & 0.034 \\
\hline BCS & 0.31 & 0.19 & 0.30 & 0.26 & 0.39 & 0.15 & 0.075 & 0.497 & 0.348 & 0.893 & 0.042 \\
\hline Feed:gain, $\mathrm{kg} / \mathrm{kg}$ & 9.6 & 10.6 & 10.5 & 10.3 & 10.2 & 10.8 & 0.20 & 0.005 & 0.935 & 0.375 & 0.062 \\
\hline
\end{tabular}

${ }^{1}$ Stocking density: (1) 100\%, pen stocked at capacity for feeding headlocks and freestalls ( 8 heifers/pen); (2) $125 \%$, pen stocked with 10 heifers/ pen; and (3) 150\%, pen stocked with 12 heifers/pen.

${ }^{2}$ Contrasts: (1) $100 \%$ vs. overstocked (125 and $150 \%$ ); and (2) 125 vs. $150 \%$.

${ }^{3} \mathrm{SS}=$ diet included wheat straw pre-processed through a tub grinder (10-cm screen) before blending into a TMR; LS = diet included unprocessed wheat straw blended into a TMR.

${ }^{4}$ ANOVA using the CV for ADG obtained from each research pen as the response variable.

this premise, a coefficient of variation $(\mathbf{C V} ; \%)$ was calculated for the ADG responses obtained from each pen, and then evaluated as a response variable by traditional ANOVA (Table 3). Data from the present study offer some agreement with previous work. Generally, variability in ADG increased with increasing stocking rate, regardless of diet; however, for the SS diet, this response was somewhat erratic across stocking rates and did not yield a detectable contrast $(P \geq 0.220)$. For the LS diet, the within-pen CV increased from 10.7 to $18.6 \%(P=0.025)$ as stocking rates were increased from 125 to $150 \%$ of capacity. Some cautions should be exercised with respect to interpretation; first, Longenbach et al. (1999) maintained a constant pen area per heifer at $3.7 \mathrm{~m}^{2}$ and considered that heifer density to be unrestrictive. Because of our barn design, the maximum within-pen density was $7.0 \mathrm{~m}^{2} /$ heifer, which is about $89 \%$ more area per heifer, and logically should reduce within-pen stress. Second, heifers in the present study were offered feed for ad libitum intake, whereas those of Longenbach et al. (1999) were limit-fed and had feed available no more than $35 \%$ of the day. For our study, the feeding management system ensured that passive heifers had feed available at all times, although it is acknowledged that the TMR remaining in the feed bunk may have been less desirable as time elapsed following distribution, particularly for the LS diet that was formulated intentionally to be highly sortable. Although not conclusive, this evaluation of the effects of stocking rate on within-pen variability of ADG generally supports the concept of greater within-pen variability as a consequence of overstocking. Ignoring the interaction of main effects, within-pen CV for the 100, 125, and $150 \%$ stocking rates across the entire trial were 11.5, 14.5 , and $16.7 \%$, respectively, where overstocked pens differed from the $100 \%$ stocking rate (15.7 vs. $11.5 \%$; $P=0.050)$, but differences between overstocked rates were only numerical $(P=0.321)$.

\section{Changes in Particle Size Distribution and Nutritive Value}

Particle Size. Changes in particle size distribution within the feed bunk during the 24 -h period following 
feed distribution are summarized in Table 4. For all particle size classifications, the diet $\times$ sampling time interaction was significant $(P \leq 0.019)$, whereas all other interactions of main effects were not $(P \geq 0.418)$. As observed by DeVries and von Keyserlingk (2009), stocking rate (or competition for feed) did not affect sorting behaviors by heifers. Therefore, only diet $\times$ sampling time interaction means are presented and discussed. As intended, the LS diet exhibited clear evidence of poor straw processing, retaining $21.7 \pm 9.42 \%$ of total dietary DM on the top screen of the Penn State Particle Separator compared with roughly half that amount (12.5 \pm $3.38 \%$ ) for the SS diet. Heifers actively discriminated against large particles, regardless of diet; particle-size concentration factors were $>1.00$ at $2 \mathrm{~h}$ postfeeding $(1300 \mathrm{~h})$ and increased in a linear $(P<0.001)$ relationship with time thereafter. For the LS diet, a tendency $(P=0.083)$ was observed for quadratic character in the relationship with sampling time, which was largely the result of static responses between the 0600 and $0900 \mathrm{~h}$ sampling times when little feed was remaining in the bunk. Large particles were discriminated against more aggressively by heifers offered the LS diet, where concentration factors first differed between diets at $2200 \mathrm{~h}$ (2.48 vs. $1.53 ; P<0.001)$ and continued through the collection of orts at $0900 \mathrm{~h}(2.82$ vs. $1.97 ; P<0.001)$.

Medium, short, and fine particles were preferred by heifers, regardless of diet. In each case, particle-size concentration factors declined across sampling times, exhibiting linear $(P \leq 0.038)$ effects of time. For the LS diet, quadratic character also was observed for short $(P=0.044)$ and fine $(P<0.001)$ particles, as well as a tendency $(P=0.091)$ for quadratic character for medium particles. As previously described for large particles, quadratic character appears to be best explained by the relative stability of these factors at the later sampling times. For the SS diet, no higher-ordered relationship was present with sampling time for any of these particle-size classes $(P \geq 0.413)$. Regardless of diet, heifer preference appeared to be associated with particle size classes; concentration factors declined to lower values, suggesting stronger preference, for fine particles followed by short and medium particle sizes. Respective minimum concentration factors for fine, short, and medium particles were $0.43,0.57$, and 0.68 for LS, and 0.69, 0.87, and 0.94 for the SS diet. Furthermore, these responses suggest overall more aggressive sorting by heifers offered the LS diet, which first differed from SS at $1900 \mathrm{~h}$ for medium particles $(0.86$ vs. $0.99 ; P<0.001)$, at $1900 \mathrm{~h}$ for short particles $(0.84$ vs. $0.97 ; P=0.002)$, and at $1600 \mathrm{~h}$ for fine particles (0.82 vs. $0.93 ; P=0.042)$. In each of these cases, heifers offered the LS diet exhibited lower $(P<0.001)$ particle-size concentration factors at all sampling times thereafter, suggesting continued preference for smaller particles compared with heifers offered the SS diet.

Generally, responses for pef followed similar patterns to those described for large particles, which included linear increases in particle-size concentration factors over time for both the SS $(P<0.001)$ and LS $(P<0.001)$ diets, suggesting overall discrimination by heifers. However, these results obscure contrasting responses for the large and medium particles comprising pef that have been described previously. Maximum concentration factors for pef in the SS and LS diets obtained at collection of orts $(0900 \mathrm{~h})$ were 1.14 and 1.26 , respectively, compared with 1.97 and 2.82 for large particles at the same bunk-sampling time. Competing discriminatory and preferential behaviors for the respective large and medium particles comprising pef by heifers offered diets diluted with wheat straw or chopped corn fodder have been observed previously, resulting in similar overall collective responses for pef that were mildly discriminatory (Coblentz et al., 2015).

Nutritive Value. As observed for particle size classes, the diet $\times$ bunk sampling time interaction was significant $(P<0.001)$ across all indices of nutritive value, and results are presented (Table 5) and discussed on that basis. It is logical that the aggressive discrimination against large particles, particularly by heifers offered the LS diet, would be corroborated by concurrent increases in nutrient concentration factors for NDF and ADL over time. For the SS diet, NDF and ADL concentrations within the feed bunk increased over time, exhibiting linear $(P \leq 0.003)$ but not quadratic $(P \geq 0.102)$ effects. Maximum factors for these respective nutritive indices were 1.08 and 1.13 , both obtained during collection of orts, suggesting only modest sorting of the well-processed straw diet. More aggressive discrimination against NDF and ADL was observed by heifers offered the LS diet; maximum nutrient concentration factors reached 1.23 and 1.39, respectively, after increasing linearly $(P<0.001)$ across sampling times. A quadratic effect also was observed for NDF $(P=0.013)$, but not for ADL $(P=0.237)$. By $1600 \mathrm{~h}$ (5 h postfeeding), heifers offered the LS diet exhibited greater NDF (1.05 vs. $1.00 ; P=0.018)$ and ADL (1.12 vs. $1.03 ; P=0.012$ ), and the magnitude of these differences became greater across later sampling times. Generally, responses for $\mathrm{CP}$ and TDN were opposite of those for NDF and ADL, thereby suggesting heifer preference that was accentuated by offering the LS diet. Although evidence was suggestive of sorting by heifers that was exacerbated when straw was processed poorly, it is difficult to relate the changes in concentrations of various particle sizes or indices of nutritive value observed with SS and LS diets directly to heifer growth performance. Previously, corn silage/alfalfa haylage 
STRAW PROCESSING AND OVERSTOCKING

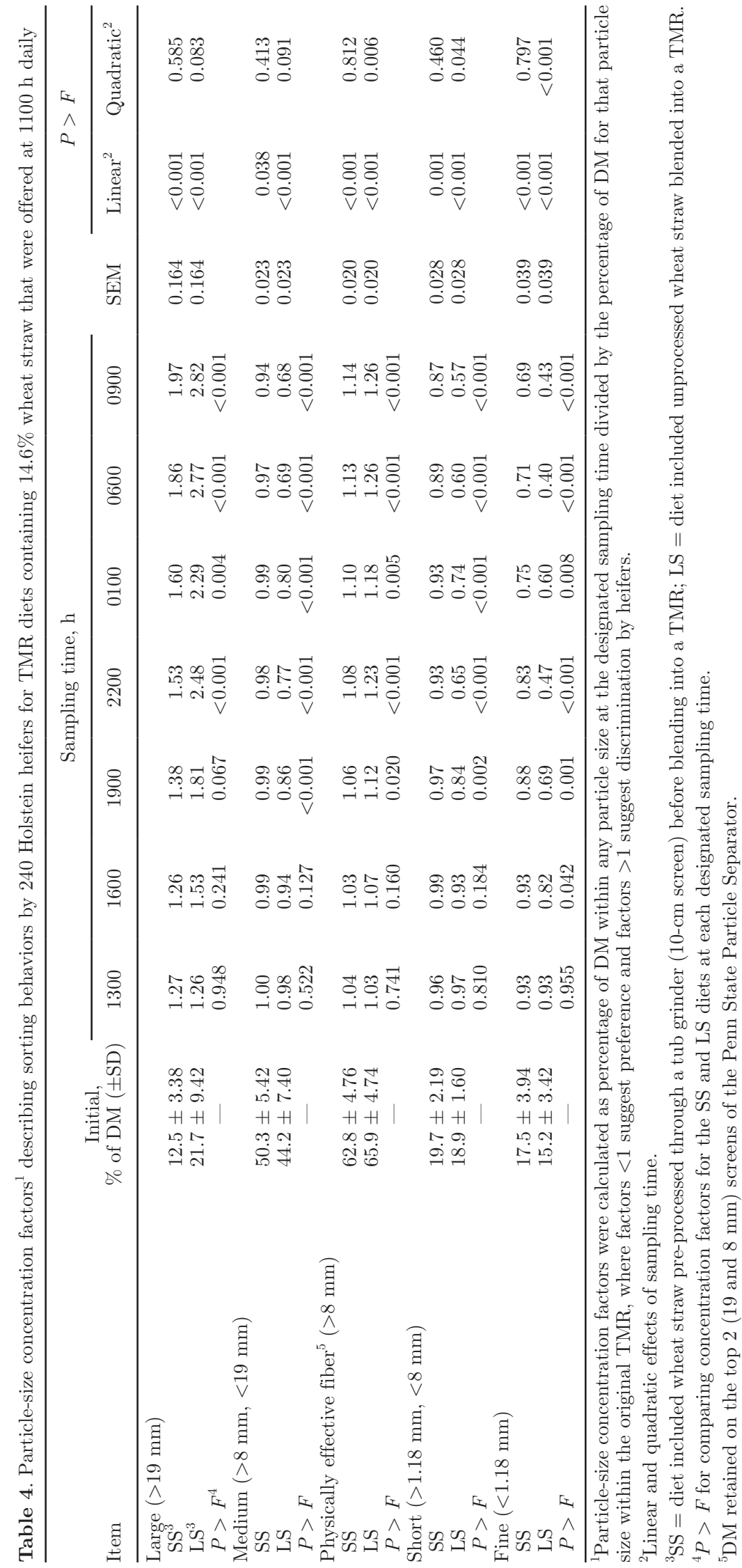


Table 5. Nutrient concentration factors ${ }^{1}$ describing sorting behaviors by 240 Holstein heifers for the nutritive value of TMR diets containing $14.6 \%$ wheat straw that were offered at $1100 \mathrm{~h}$ daily

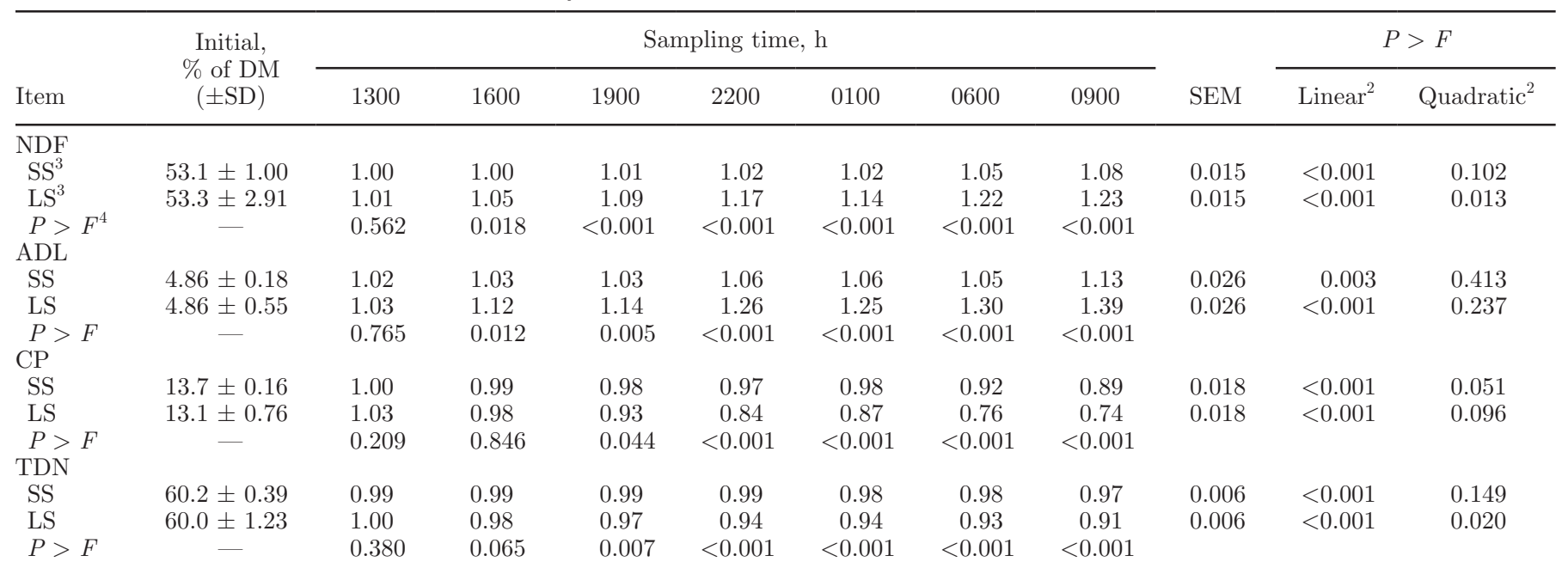

${ }^{1}$ Nutrient concentration factor was calculated as the concentration of any nutrient at the designated sampling time divided by the concentration of that nutrient within the original TMR, where factors $<1$ suggest preference and factors $>1$ suggest discrimination by heifers.

${ }^{2}$ Linear and quadratic effects of sampling time.

${ }^{3} \mathrm{SS}=$ diet included wheat straw pre-processed through a tub grinder (10-cm screen) before blending into a TMR; LS = diet included unprocessed wheat straw blended into a TMR.

${ }^{4} P>F$ for comparing concentration factors for the SS and LS diets at each designated sampling time.

diets diluted with eastern gamagrass haylage, wheat straw, or chopped corn fodder that differed radically with respect to sortability could not be directly related to heifer growth performance or within-pen variability of daily weight gains (Coblentz et al., 2015). As in the present study, diets were offered for ad libitum intake, but with minimal orts (Shaver and Hoffman, 2010); however, pens were not overstocked in that study, nor could the within-pen density of $10.6 \mathrm{~m}^{2} /$ heifer be considered restrictive. Although it remains unclear how diet sortability affects heifer growth performance, or if sortability effects become more discernable under more stressful growing environments, circumstantial evidence suggests that the feeding concepts for dilutant forages recommended by Shaver and Hoffman (2010) are at least partially effective in limiting within-pen variability of heifer growth responses.

\section{Standing Time Assessments}

The use of data loggers, as described by Ito et al. (2009), was effective in quantifying the elapsed daily time that heifers were standing. This approach has been used successfully with lactating (Ito et al., 2009; Krawczel et al., 2012) and prepartum (Lobeck-Luchterhand et al., 2015) cows; however, dairy heifers are often bored, curious, and more active than cows, and the use of data loggers required daily attention to prevent heifers from loosening the affixed data loggers. Never- theless, the data obtained from this technique provides some indirect evidence that heifers compensated for stall unavailability, primarily by standing (Table 6). Neither the main effect of $\operatorname{diet}(P \geq 0.333)$, nor the diet $\times$ stocking density interaction $(P \geq 0.754)$, affected any of the response variables obtained electronically via data loggers. The main effect of stocking rate was significant for cumulative daily standing time $(P$ $=0.002)$, as well as the mean length of standing bouts $(P=0.027)$. The number of standing bouts was not affected by any aspect of the treatment structure $(P$ $\geq 0.663)$. Overall, heifers in overstocked pens stood 38 min/d longer, and also stood 6 min longer/bout than heifers assigned to pens stocked at $100 \%$ of capacity. Several studies (Olofsson, 1999; Huzzey et al., 2006; González et al., 2008a,b) have reported increased inactive standing time or decreased lying times associated with competition at the feed bunk, but these studies were not generally complicated further by competition for free stalls or lying space. Other studies (Fregonesi et al., 2007; Krawczel et al., 2012; Telezhenko et al., 2012) have associated the overstocking ( $>1 \mathrm{cow} / \mathrm{stall})$ of lactating cows with reduced lying times. Generally, stocking rates of $\leq 100 \%$ have been required to allow lactating cows at least $12 \mathrm{~h} / \mathrm{d}$ of lying time, but this standard (Canadian Code of Practice; Dairy Farmers of Canada, 2009) has been difficult to maintain at greater stocking rates (Fregonesi et al., 2007; Krawczel et al., 2012). One recent survey of Canadian dairy farms 
Table 6. Daily time heifers spent standing, as well as the mean duration of standing bouts and the number of bouts per day for 240 Holstein dairy heifers

\begin{tabular}{lccc}
\hline Item & $\begin{array}{c}\text { Standing time, } \\
\text { min/d }\end{array}$ & $\begin{array}{c}\text { Standing bouts, } \\
\text { no./d }\end{array}$ & $\begin{array}{c}\text { Standing duration, } \\
\text { min/bout }\end{array}$ \\
\hline Stocking rate, ${ }^{1} \%$ & 583 & & \\
100 & 612 & 11.9 & 53 \\
125 & 629 & 11.6 & 58 \\
150 & 8.0 & 0.35 & 60 \\
SEM & & & 1.9 \\
Contrast, $P>F$ & 0.002 & 0.772 & 0.027 \\
$100 \%$ vs. overstocked $(125$ and $150 \%)$ & 0.152 & 0.398 & 0.563 \\
125 vs. $150 \%$ & & & \\
\hline
\end{tabular}

${ }^{1}$ Stocking density: (1) 100\%, pen stocked at capacity for feeding headlocks and freestalls (8 heifers/pen); (2) $125 \%$, pen stocked with 10 heifers/pen; and (3) 150\%, pen stocked with 12 heifers/pen.

(Charlton et al., 2014) was unable to link stall-stocking rate with lying behavior, but no farm with stocking rates $>100 \%$ met the $12-\mathrm{h} / \mathrm{d}$ standard described previously. Generally, our results for overstocked dairy heifers are consistent with these previously reports; standing times were increased with overstocking; however, total daily standing times for all stocking rates (583 to $629 \mathrm{~min} / \mathrm{d}$; 9.7 to $10.5 \mathrm{~h} / \mathrm{d}$ ) were well under the $12 \mathrm{~h} / \mathrm{d}$ threshold, in part because no standing time was required for milking activities.

\section{Hygiene}

Neither diet $(P \geq 0.126)$, nor the diet $\times$ stocking rate interaction $(P \geq 0.805)$ affected any response variable describing heifer hygiene (Table 7) as determined on a 4-point scale (Cook and Reinemann, 2007). Hygiene scores for both legs $(\leq 2.3)$ and flanks $(\leq 1.9)$ indicated that heifers maintained an acceptable standard of hygiene, regardless of stocking rate. Cook and Reinemann (2007) have reported, based on evaluation of 46 Wisconsin dairy herds, a median of $59 \%$ of cows scoring either of 3 or 4 for lower legs, and a median of $47 \%$ within the $25 \%$ of herds that exhibited the best hygiene. For flanks, a median of $15 \%$ of cows scored either 3 or 4 .

In the present study, scores for both legs $(P=0.047)$ and flanks $(P=0.072)$ were either greater or tended to be greater for overstocked pens compared with those stocked at capacity, but no difference $(P \geq 0.440)$ was observed between overstocked rates for either response variable. Moreover, the magnitude of these increases in hygiene scores obtained by overstocking was relatively minor, consisting of 0.2 and 0.3 units for legs and flanks, respectively. Generally, these findings are consistent with those reported by Krawczel et al. (2012), where no differences in hygiene of udders, legs, or soiled teats were observed when lactating cows were stocked at 100 and $142 \%$ of capacity. Perhaps more importantly, our within-pen $\mathrm{CV}$ for leg scores indicated greater variability within overstocked pens (14.4 vs. $9.0 \% ; P=0.045)$, and a similar response was observed for flanks $(34.2$ vs. $23.8 \% ; P=0.018)$. This suggests that a pen mean for hygiene scores may be affected only minimally by overstocking at rates ranging up to $150 \%$ of capacity, but this response masks significant increases in withinpen variability that are likely related to heifers within

Table 7 . Hygiene scores as affected by pen stocking rate, where $1=$ no manure and $4=$ caked-on manure (Cook and Reinemann, 2007), for 240 Holstein dairy heifers

\begin{tabular}{lcccc}
\hline Item & Legs & Legs CV, ${ }^{1} \%$ & Flanks & Flanks CV, ${ }^{1} \%$ \\
\hline Stocking rate ${ }^{2} \%$ & & & & \\
100 & 2.1 & 9.0 & 1.6 & 23.8 \\
125 & 2.3 & 12.7 & 1.8 & 31.9 \\
150 & 2.3 & 16.1 & 1.9 & 36.4 \\
SEM & 0.08 & 2.02 & 0.08 & 3.18 \\
Contrast, $P>F$ & & & & \\
$100 \%$ vs. Overstocked (125 and 150\%) & 0.047 & 0.045 & 0.072 & 0.018 \\
125 vs. $150 \%$ & 0.752 & 0.262 & 0.440 & 0.329 \\
\hline
\end{tabular}

${ }^{1}$ Coefficient of variation for hygiene scores used as a response variable and subjected to ANOVA.

${ }^{2}$ Stocking density: (1) $100 \%$, pen stocked at capacity for feeding headlocks and freestalls ( 8 heifers/pen); (2) 125\%, pen stocked with 10 heifers/pen; and (3) 150\%, pen stocked with 12 heifers/pen. 
overstocked pens occasionally choosing to rest in the alleys due to fatigue, frustration, or lack of discernment.

\section{CONCLUSIONS}

The compounding effects of overstocking at the feed bunk, coupled with similar overstocking rates for free stalls, were examined for Holstein dairy heifers offered alfalfa haylage/corn silage diets diluted with either poorly or well-processed wheat straw. Based on changes in concentration of specific particle size classes over time, heifers exhibited sorting behaviors, regardless of diet, but exhibited more aggressive sorting behaviors when straw was poorly processed. In this study, heifers preferentially selected medium, small, and fine particles, but discriminated against large particles. Similarly, heifers favored specific nutrients, such as CP and TDN, but actively discriminated against forage fiber-related components, such as NDF and ADL. However, during the 91-d feeding trial, it was not possible to relate these temporal concentration changes within the feed bunk to heifer growth performance. For both diets, ADG declined as stocking density was increased, but this occurred primarily between the 100 and $125 \%$ stocking rates for SS and between 125 and $150 \%$ stocking rates for LS. Ignoring interactions, within-pen variability for ADG increased from 11.5 to $16.7 \%$ as stocking rate increased from 100 to $150 \%$ of capacity, thereby providing supportive, but not conclusive, evidence that overstocking increases within-pen variability with respect to weight gains as suggested in several other studies.

\section{ACKNOWLEDGMENTS}

Mention of trade names or commercial products in this article is solely for the purpose of providing specific information, and does not imply either recommendation or endorsement by the U.S. Department of Agriculture. The research was supported through appropriated USDA-Agricultural Research Service funds (Current Research Information System Project \#509012630-005-00D).

\section{REFERENCES}

Association of Official Analytical Chemists. 1990. Official Method \#920.29. Official Methods of Analysis. 15th ed. AOAC, Arlington, VA.

AOAC International. 1998a. Official Method \#988.05. Official Methods of Analysis. 16th ed. AOAC, Arlington, VA.

AOAC International. 1998b. Official Method \#990.03. Official Methods of Analysis. 16th ed. AOAC, Arlington, VA.

Charlton, G. L., D. B. Haley, J. Rushen, and A. M. de Passillé. 2014 Stocking density, milking duration, and lying times of lactating cows on Canadian freestall dairy farms. J. Dairy Sci. 97:2694-2700.
Coblentz, W. K., N. M. Esser, P. C. Hoffman, and M. S. Akins. 2015 Growth performance and sorting characteristics of corn silagealfalfa haylage diets with or without forage dilution offered to replacement Holstein dairy heifers. J. Dairy Sci. 98:8018-8034.

Coblentz, W. K., P. C. Hoffman, N. M. Esser, and M. G. Bertram. 2012. Using eastern gamagrass to construct diets that limit intake and caloric density for dairy heifers. J. Dairy Sci. 95:6057-6071.

Cook, N. B., and D. J. Reinemann. 2007. A toolbox for assessing cow, udder, and teat hygiene. Pages 31-43 in Proc. 46th Annual Mtg. Natl. Mastitis Council, San Antonio, TX. Natl. Mastitis Council, Madison, WI.

Dairy Farmers of Canada. 2009. Code of Practice for the Care and Handling of Dairy Cattle. Dairy Farmers of Canada. Ottawa, ON, Canada.

DeVries, T. J., and M. A. G. von Keyserlingk. 2009. Competition for feed affects the feeding behavior of growing dairy heifers. J. Dairy Sci. 92:3922-3929.

DeVries, T. J., M. A. G. von Keyserlingk, and D. M. Weary. 2004 Effect of feeding space on the inter-cow distance, aggression, and feeding behavior of free-stall housed lactating dairy cows. J. Dairy Sci. 87:1432-1438.

Esser, N. M., P. C. Hoffman, W. K. Coblentz, M. W. Orth, and K. A. Weigel. 2009. The effect of dietary phosphorus on bone development in dairy heifers. J. Dairy Sci. 92:1741-1749.

Fregonesi, J. A., C. B. Tucker, and D. M. Weary. 2007. Overstocking reduces lying time in dairy cows. J. Dairy Sci. 90:3349-3354.

Goering, H. K., and P. J. Van Soest. 1970. Forage Fiber Analyses (Apparatus, Reagents, Procedures, and Some Applications). Agric. Handbook No. 379. USDA-ARS, Washington, DC.

González, L. A., A. Ferret, X. Manteca, J. L. Ruíz-de-la-Torre, S. Calsamiglia, M. Devant, and A. Bach. 2008a. Effect of the number of concentrate feeding places per pen on performance, behavior, and welfare indicators of Friesian calves during the first month after arrival at the feedlot. J. Anim. Sci. 86:419-431.

González, L. A., A. Ferret, X. Manteca, J. L. Ruíz-de-la-Torre, S. Calsamiglia, M. Devant, and A. Bach. 2008b. Performance, behavior, and welfare, of Friesian heifers housed in pens with two, four, and eight individuals per concentrate feeding place. J. Anim. Sci. 86:1446-1458

Greter, A. M., T. J. DeVries, and M. A. G. von Keyserlingk. 2008. Nutrient intake and feeding behavior of growing dairy heifers: effects of dietary dilution. J. Dairy Sci. 91:2786-2795.

Hoffman, P. C. 1997. Optimum body size of Holstein replacement heifers. J. Anim. Sci. 75:836-845.

Hoffman, P. C., N. M. Brehm, S. G. Price, and A. Prill-Adams. 1996. Effect of accelerated postpubertal growth and early calving on lactation performance of primiparous Holstein heifers. J. Dairy Sci. 79:2024-2031.

Hoffman, P. C., C. R. Simson, and M. Wattiaux. 2007. Limit feeding of gravid Holstein heifers: effect on growth, manure nutrient excretion, and subsequent early lactation performance. J. Dairy Sci. 90:946-954.

Hoffman, P. C., K. A. Weigel, and R. M. Wernberg. 2008. Evaluation of equations to predict dry matter intake of dairy heifers. J. Dairy Sci. 91:3699-3709.

Huzzey, J. M., T. J. deVries, P. Valois, and M. A. G. von Keyserlingk. 2006. Stocking density and feed barrier design affect the feeding and social behavior of dairy cattle. J. Dairy Sci. 89:126-133.

Ito, K., D. M. Weary, and M. A. G. von Keyserlingk. 2009. Lying behavior: Assessing within- and between-herd variation in free-stallhoused dairy cows. J. Dairy Sci. 92:4412-4420.

Keys, J. E., R. E. Pearson, and P. D. Thompson. 1978. Effect of feedbunk stocking density on weight gains and feeding behavior of yearling Holstein steers. J. Dairy Sci. 61:448-454.

Kononoff, P. J., A. J. Heinrichs, and D. R. Buckmaster. 2003. Modifications of Penn State forage and total mixed ration particle separator and the effects of moisture content on measurements. J. Dairy Sci. 86:1858-1863.

Krawczel, P. D., C. S. Mooney, H. M. Dann, M. P. Carter, R. E. Butzler, C. S. Ballard, and R. J. Grant. 2012. Effect of alternative 
models for increasing stocking density on the short-term behavior and hygiene of Holstein dairy cows. J. Dairy Sci. 95:2467-2475.

Kruse, K. A., D. K. Combs, N. M. Esser, W. K. Coblentz, and P. C. Hoffman. 2010. Evaluation of potential carryover effects associated with limit feeding gravid Holstein heifers. J. Dairy Sci. 93:5374-5384.

Lammers, B. P., D. R. Buckmaster, and A. J. Heinrichs. 1996. A simple method for the analysis of particle sizes of forages and total mixed rations. J. Dairy Sci. 79:922-928.

Leonardi, C., and L. E. Armentano. 2003. Effect of quantity, quality, and length of alfalfa hay on selective consumption by dairy cows. J. Dairy Sci. 86:557-564.

Lobeck-Luchterhand, K. M., P. R. B. Silva, R. C. Chebel, and M. I. Endres. 2015. Effect of stocking density on social, feeding, and lying behavior of prepartum dairy animals. J. Dairy Sci. 98:240-249.

Loerch, S. C. 1990. Effects of feeding growing cattle high-concentrate diets at a restricted intake on feedlot performance. J. Anim. Sci. 68:3086-3095.

Longenbach, J. I., A. J. Heinrichs, and R. E. Graves. 1999. Feed bunk length requirements for Holstein dairy heifers. J. Dairy Sci. 82:99109 .

NRC. 2001. Nutrient Requirements of Dairy Cattle. 7th rev. ed. National Academy Press, Washington, DC.

Olofsson, J. 1999. Competition for total mixed diets fed for ad libitum intake using one or four cows per feeding station. J. Dairy Sci. $82: 69-79$

Proudfoot, K. L., D. M. Veira, D. M. Weary, and M. A. G. von Keyserlingk. 2009. Competition at the feed bunk changes the feeding, standing, and social behavior of transition dairy cows. J. Dairy Sci. 92:3116-3123.

Schulte, E. E., J. B. Peters, and P. R. Hodgson. 1987. Wisconsin procedures for soil testing, plant analysis and feed and forage analysis. Dept. Soil Sci. Bull. No. 6. University of Wisconsin, Madison.

Shaver, R. D., and P. C. Hoffman. 2010. Use of straw in dairy cattle diets. Focus on Forage Vol. 12: No. 2. University of Wisconsin Extension, Madison.

St-Pierre, N. R. 2007. Design and analysis of pen studies in the animal sciences. J. Dairy Sci. 90(E. Suppl.):E87-E89.

Telezhenko, E., M. A. G. von Keyserlingk, A. Talebi, and D. M. Weary. 2012. Effect of pen size, group size, and stocking density on activity in freestall-housed dairy cows. J. Dairy Sci. 95:3064-3069.

Van Soest, P. J., J. B. Robertson, and B. A. Lewis. 1991. Methods for dietary fiber, neutral detergent fiber, and nonstarch polysaccharides in relation to animal nutrition. J. Dairy Sci. 74:3583-3597.

Wildman, E. E., G. M. Jones, P. E. Wagner, R. L. Boman, H. F. Troutt Jr., and T. N. Lesch. 1982. A dairy cow body condition scoring system and its relationship to selected production characteristics. J. Dairy Sci. 65:495-501.

Zanton, G. I., and A. J. Heinrichs. 2007. The effects of controlled feeding of a high-forage or high-concentrate ration on heifer growth and first lactation milk production. J. Dairy Sci. 90:3388-3396.

Zanton, G. I., and A. J. Heinrichs. 2008. Rumen digestion and nutritional efficiency of dairy heifers limit-fed a high forage ration to four levels of dry matter intake. J. Dairy Sci. 91:3579-3588. 